九州大学学術情報リポジトリ

Kyushu University Institutional Repository

PLA法を用いたHERファミリー二量体の定量化および オシメルチニブを投与された非小細胞肺癌患者にお ける臨床的な解析

劉，仁鵬

http://hdl. hand le. net/2324/4496010

出版情報：Kyushu University，2021，博士（医学），課程博士 バージョン：

権利関係: (c) 2021 Elsevier B.V. All rights reserved. 


\title{
Quantification of HER family dimers by proximity ligation assay and its clinical evaluation in non-small cell lung cancer patients treated with osimertinib
}

\author{
Renpeng Liu ${ }^{a}$, Keiichi Ota ${ }^{\text {a,b, }}$, Eiji Iwama ${ }^{a}$, Yasuto Yoneshima ${ }^{a}$, Kentaro Tanaka ${ }^{\text {a }}$ \\ Hiroyuki Inoue $^{\mathrm{a}, \mathrm{c}}$, Tetsuzo Tagawa ${ }^{\mathrm{d}}$, Yoshinao Oda ${ }^{\mathrm{e}}$, Masaki Mori ${ }^{\mathrm{d}}$, Yoichi Nakanishi ${ }^{\mathrm{f}}$, \\ Isamu Okamoto ${ }^{a}$ \\ ${ }^{a}$ Research Institute for Diseases of the Chest, Graduate School of Medical Sciences, Kyushu University, 3-1-1 Maidashi, Higashi-ku, Fukuoka, 812-8582, Japan \\ ${ }^{\mathrm{b}}$ Department of Comprehensive Clinical Oncology, Faculty of Medical Sciences, Kyushu University, 3-1-1 Maidashi, Higashi-ku, Fukuoka, 812-8582, Japan \\ ${ }^{\mathrm{c}}$ Department of Respiratory Medicine, Fukuoka University Hospital, 7-45-1 Nanakuma, Jonan-ku, Fukuoka, 814-0180, Japan \\ ${ }^{\mathrm{d}}$ Department of Surgery and Science, Graduate School of Medical Sciences, Kyushu University, 3-1-1 Maidashi, Higashi-ku, Fukuoka, 812-8582, Japan \\ ${ }^{\mathrm{e}}$ Department of Anatomic Pathology, Graduate School of Medical Sciences, Kyushu University, 3-1-1 Maidashi, Higashi-ku, Fukuoka, 812-8582, Japan \\ ${ }^{\mathrm{f}}$ Kitakyushu City Hospital Organization, 2-1-1 Bashaku, Kokurakita-ku, Kitakyushu, 802-8561, Japan
}

\section{A R T I C L E I N F O}

\section{Keywords:}

Human epidermal growth factor receptor (HER)

Heterodimer

Proximity ligation assay (PLA)

Epidermal growth factor receptor (EGFR)

Tyrosine kinase inhibitor (TKI)

Non-small cell lung cancer (NSCLC)

\begin{abstract}
A B S T R A C T
Objectives: The epidermal growth factor receptor (EGFR, also known as Her1) is a member of the human epidermal growth factor receptor (HER) family of proteins and a target of tyrosine kinase inhibitors (TKIs) in the treatment of non-small cell lung cancer (NSCLC) positive for activating mutations ofEGFR. Signal transduction by HER family proteins is dependent on their homo- or heterodimerization, but little is known of the relation between the relative proportions of such dimers of Her1 and sensitivity to EGFR-TKIs. We here investigated the feasibility of assessing this relation with the in situ proximity ligation assay (PLA) technique, which is able to detect the interaction of two proteins of interest when they are in close proximity.

Materials and methods: In situ PLA was applied to detect Her1 homodimers and Her1 heterodimers in NSCLC cell lines and tissue specimens positive for EGFR activating mutations.

Results: In situ PLA allowed visualization and quantitative assessment of Her1 homodimers as well as of Her1 heterodimers with Her2, Her3, or Her4 not only in NSCLC cell lines but also in NSCLC tissue specimens obtained from various anatomic sites and by different collection methods. Treatment of NSCLC cell lines with EGFR-TKIs resulted in a decrease in the number of Her1 dimers, with the effect on homodimers being greater than that on heterodimers. A high ratio of Her1 heterodimers to homodimers was associated with poor progression-free survival in NSCLC patients treated with osimertinib.

Conclusion: In situ PLA allows the detection of HER family dimers in NSCLC tissue, and quantitative assessment of Her1 homo- and heterodimers may prove informative for prediction of the response of NSCLC patients to EGFRTKI treatment.
\end{abstract}

\section{Introduction}

The human epidermal growth factor receptor (HER) family of receptor tyrosine kinases comprises Her1 (also known as EGFR or ErbB1), Her2 (Neu, ErbB2), Her3 (ErbB3), and Her4 (ErbB4) [1]. Signal transduction by HER family proteins is dependent on receptor dimerization [2], with such dimers including both homodimers and heterodimers [3].
Dimer formation induces receptor autophosphorylation as well as the activation of downstream signaling molecules including those of the Raf-MEK-MAPK and PI3K-Akt pathways that regulate cell proliferation, differentiation, and migration as well as epithelial-mesenchymal transition and angiogenesis [4-6]. Members of the HER family are frequently overexpressed in human carcinomas. High expression levels of mutant forms of the epidermal growth factor receptor (EGFR) have

\footnotetext{
* Corresponding author at: Research Institute for Diseases of the Chest, Graduate School of Medical Sciences, Kyushu University, 3-1-1 Maidashi, Higashi-ku, Fukuoka, 812-8582, Japan.

E-mail address: oota-k@kokyu.med.kyushu-u.ac.jp (K. Ota).
} 
been associated with a longer progression-free survival (PFS) in individuals with non-small cell lung cancer (NSCLC) [7]; those of EGFR, Her3, or Her4 are independent predictors of poor PFS and overall survival in osteosarcoma [8]; and homodimers or heterodimers of Her2 are related to a shorter relapse-free survival and overall survival in women with breast cancer [9].

Activating mutations of EGFR in individuals with NSCLC tend to cluster in the region spanning exons 18-21 [10]. The most common such mutations are exon-19 deletions and an L858R point mutation in exon 21 [11], with these mutations having been found to serve as biomarkers for a high response rate to treatment with EGFR tyrosine kinase inhibitors (TKIs) [12]. First- or third-generation EGFR-TKIs such as erlotinib and osimertinib specifically block EGFR-induced activation of downstream signaling as a result of reversible or irreversible binding to the ATP binding site of EGFR, respectively. By contrast, second-generation EGFR-TKIs such as afatinib, dacomitinib, poziotinib, and pyrotinib are highly potent inhibitors not only of EGFR but also of Her2 and Her4 as a result of their irreversible covalent binding to the ATP binding site of these HER family members, and they show clinically relevant efficacy for NSCLC positive for HER2 alterations [13-15]. Patients with activating EGFR mutations treated with first- or second-generation EGFR-TKIs inevitably develop resistance to these drugs [16-18]. A secondary T790 M point mutation in exon 20 of EGFR is the cause of acquired resistance to EGFR-TKI therapy in $\sim 60 \%$ of such treated patients with EGFR-mutated NSCLC [19,20]. The third-generation EGFR-TKI osimertinib is highly selective for forms of the receptor harboring both activating mutations and T790M and has therefore been administered for the treatment of NSCLC patients with acquired resistance to first- or second-generation EGFR-TKIs due to the development of T790M [21,22].

The in situ proximity ligation assay (PLA) technique extends the capability of traditional immunostaining to directly detect proteins, protein-protein interactions, and protein modifications with high specificity and sensitivity [23]. The proteins of interest are recognized by primary antibodies and subsequently by two PLA probes that are conjugated to specific oligonucleotides. If the proteins and bound oligonucleotides are separated by a distance of $<40 \mathrm{~nm}$, the oligonucleotides are ligated, subjected to rolling-circle amplification, and detected with fluorescent complementary oligonucleotides [24]. We previously showed that EGFR (Her1) homodimers could be visualized and quantitated in both NSCLC cell lines and tissue specimens by in situ PLA [25]. We have now applied this approach to the detection of other HER family dimers in NSCLC cell lines and clinical specimens with EGFR mutations. In addition, we evaluated the relation between the abundance of HER family dimers and PFS in NSCLC patients positive for the T790M mutation of EGFR who received second-line treatment with osimertinib.

\section{Materials and methods}

\subsection{Cell culture and reagents}

The human NSCLC cell lines HCC827 and H4006 were obtained from American Type Culture Collection (Manassas, VA, USA), whereas 11_18 and PC9 cells were obtained as previously described [26]. The cells were maintained under an atmosphere of $5 \% \mathrm{CO}_{2}$ at $37^{\circ} \mathrm{C}$ in RPMI 1640 medium (Gibco, Carlsbad, CA, USA) supplemented with $10 \%$ heat-inactivated fetal bovine serum and $1 \%$ penicillin-streptomycin. Afatinib (LKT Laboratories, St. Paul, MN, USA), erlotinib (LKT Laboratories), and osimertinib (ChemScene, Monmouth Junction, NJ, USA) were dissolved in dimethyl sulfoxide (Fujifilm Wako Pure Chemical Industries, Osaka, Japan) and stored at $-20^{\circ}$ or $-80^{\circ} \mathrm{C}$ for up to 2 weeks. For in situ PLA, cells were grown to $70 \%$ confluence on 12-mm-diameter coverslips (Matsunami, Osaka, Japan) placed in 24-well plates (Corning, Corning, NY, USA).

\subsection{Patients and specimen collection}

Tumor specimens positive for the T790M mutation of EGFR were obtained from 26 NSCLC patients who had undergone surgical resection, transbronchial lung biopsy (TBLB), bone biopsy, lymph node biopsy, or endobronchial ultrasound-guided transbronchial needle aspiration (EBUS-TBNA) after first-line treatment with erlotinib or afatinib and before second-line treatment with osimertinib. The specimens were collected between June 2014 and March 2019 at Kyushu University Hospital. Activating EGFR mutations in these patients included an exon19 deletion in 17 individuals and the L858R point mutation in nine. Tissue specimens were fixed with $10 \%$ neutral buffered formalin, embedded in paraffin, sectioned, and processed for PLA analysis. The study conformed to the tenets of the Declaration of Helsinki and was approved by the Institutional Review Board of Kyushu University Hospital. All patients provided written informed consent.

\subsection{Cell viability assay}

Cells were seeded in 96-well plates at a density of 5000 per well and were cultured for $24 \mathrm{~h}$ before the addition of erlotinib, afatinib, or osimertinib at various concentrations $(0.5-5000 \mathrm{nM})$ and incubation for an additional $72 \mathrm{~h}$. Cell viability was then determined with a Cell Counting Kit-8 (Dojindo, Osaka, Japan).

\subsection{In situ PLA with cells and tissue samples}

Cells were fixed for $20 \mathrm{~min}$ with $4 \%$ paraformaldehyde in phosphate-buffered saline (PBS) and then permeabilized for $10 \mathrm{~min}$ with $0.2 \%$ Triton X-100 in PBS. Paraffin-embedded tumor sections were depleted of paraffin, rehydrated, and washed with PBS. Tissue specimens were subjected to antigen retrieval with the use of ImmunoSaver (Wako). Detection of HER family dimers was performed with mouse antibodies to Her1 (1:50 dilution; Santa Cruz Biotechnology, Dallas, TX, USA), rabbit anti-Her1 (1:500; Abcam, Cambridge, MA, USA), mouse anti-Her2 (1:500, Abcam), mouse anti-Her3 (1:50, Santa Cruz Biotechnology), and mouse anti-Her4 (1:100, Abcam). PLA was conducted with pairs of primary antibodies as described in the Duolink PLA Technology protocol (Sigma-Aldrich, St. Louis, MO, USA). Cells were incubated with the PLA probes in a humidified chamber for $1 \mathrm{~h}$ at $37^{\circ} \mathrm{C}$. Hybridization, ligation, amplification, and detection were performed as per the manufacturer's instructions. Samples were incubated for $15 \mathrm{~min}$ with Duolink in situ Mounting Medium (Sigma-Aldrich) for staining of nuclei before the detection of PLA signals with a fluorescence microscope (BZX700; Keyence, Osaka, Japan). Images were obtained from at least nine randomly selected fields for each coverslip. BZ-X analyzer software (Keyence) was applied to draw regions of interest around cells and to quantify the number of PLA signals per cell above a specified signal threshold. All quantification and analysis were performed on unenhanced data.

\subsection{Statistical analysis}

All experiments were performed at least three times. Correlation analysis was performed with Pearson's test. Kaplan-Meier curves were generated to calculate PFS for the study patients. A $P$ value of $<0.05$ was considered statistically significant. All statistical analysis was performed with GraphPad Prism 7.0.

\section{Results}

\subsection{Detection of HER family dimers in NSCLC cell lines and tissue}

We first investigated the heterodimerization of HER family proteins by in situ PLA in NSCLC cell lines. For detection of Her1:Her2 heterodimers, the cells were exposed simultaneously to primary antibodies to 
Her1 and those to Her2 (Fig. 1A). We confirmed that the primary antibodies to both proteins were necessary for heterodimer signal detection. We then attempted to detect homodimers and heterodimers of HER family proteins in NSCLC cell lines and tumor specimens positive for EGFR activating mutations. We detected Her1 (EGFR) homodimers as well as heterodimers of Her1 and Her2 both in the 11_18 cell line and in NSCLC tissue obtained by TBLB or surgical resection (Fig. 1B). Furthermore, Her1:Her2 heterodimer signals were similarly detected in NSCLC tissue obtained by bone biopsy, lymph node biopsy, or EBUSTBNA (Fig. 1C). Whereas we previously described the visualization of Her1 homodimer signals by in situ PLA [25], our present results thus showed that PLA technology is also able to detect heterodimers of the HER family both in cell lines and in tumor tissue obtained from different anatomic sites and by different techniques.

\subsection{Relation between the effect of EGFR-TKIs on cell viability and the number of Her1 dimer signals in NSCLC cell lines}

The median inhibitory concentration $\left(\mathrm{IC}_{50}\right)$ was determined for the EGFR-TKIs erlotinib, afatinib, and osimertinib in four NSCLC cell lines (11_18, HCC827, HCC4006, and PC9) positive for EGFR activating mutations. Each drug attenuated the viability of each cell line in a concentration-dependent manner (Fig. 2A), with the drug sensitivity of each cell line decreasing in the rank order of afatinib $>$ osimertinib > erlotinib. We then quantitated Her1 homodimers and Her1 heterodimers (Her1:Her2, Her1:Her3, and Her1:Her4) in these four cell lines before and after exposure to erlotinib, afatinib, or osimertinib at the corresponding IC 50 for $24 \mathrm{~h}$ (Fig. 2B, Supplementary Figs. S1 and S2). The numbers of Her1 homodimers and Her1 heterodimers in each cell line were reduced after treatment with each EGFRTKI compared with those apparent in control cells (Fig. 2C). The number of homodimers tended to be reduced to a greater extent than the number of heterodimers in the cells exposed to EGFR-TKIs. The effect of afatinib on the number of Her1 heterodimers in each cell line was greater than that of osimertinib, which in turn was greater than that of erlotinib, with the rank order of these effects being the same as that for drug cytotoxicity.

To examine further the relation between the numbers of Her1 homodimers and heterodimers and EGFR-TKI sensitivity, we analyzed the potential correlation between the ratio of heterodimers to homodimers after EGFR-TKI treatment and the IC $_{50}$ of EGFR-TKIs in the four NSCLC cell lines (Fig. 2D). The ratio of heterodimers to homodimers was indeed found to show a significant positive correlation with the $\mathrm{IC}_{50}$ of EGFR-TKIs $(P<0.05)$, suggesting that this ratio is a potential predictor of EGFR-TKI sensitivity.

\subsection{Relation between the Her1 heterodimer/homodimer ratio and PFS in osimertinib-treated NSCLC patients with EGFR mutations}

To test whether the ratio of Her1 heterodimers to Her1 homodimers might serve as a predictive marker for EGFR-TKI treatment in patients with EGFR mutation-positive NSCLC, we collected tissue specimens from 26 such patients after they had developed T790M-associated drug resistance during first-line treatment with erlotinib or afatinib and before they underwent second-line treatment with osimertinib. The Her1 heterodimer/homodimer ratio was successfully determined for all of these patients by in situ PLA (Table 1 ) and was classified as high ( $n=13)$ or low $(n=13)$ according to the median value of 4.79. KaplanMeier analysis revealed that PFS during osimertinib treatment was shorter for patients with a high Her1 heterodimer/homodimer ratio than for those with a low one (Fig. 3), suggesting that this ratio may be a predictive marker for EGFR-TKI treatment in patients with EGFRmutated NSCLC.

\section{Discussion}

The in situ PLA technique has been applied to the study of proteinprotein interactions in a variety of solid tumors. We here demonstrated the detection of homodimers and heterodimers of the HER family with this technique in both NSCLC cell lines and formalin-fixed NSCLC tissue positive for EGFR activating mutations. We further showed that it was possible to quantify HER family dimers in tumor specimens derived from different anatomic sites and obtained by different methods. Previous studies have described application of the PLA method to the analysis of HER family dimers in fixed tumor tissue from patients with breast cancer, esophageal cancer, or glioblastoma [9,27,28]. Furthermore, we previously detected PLA signals for the EML4-ALK fusion protein in NSCLC cells harboring the corresponding fusion oncogene [25]. In situ PLA thus appears to be widely applicable to such analysis in cancer patients.

Overexpression or activation of EGFR occurs frequently in NSCLC [29]. EGFR (Her1) activates intracellular signaling pathways through formation of homodimers or of heterodimers with other members of the HER family [30]. Such signaling is blocked as a result of the interaction of EGFR-TKIs with the ATP binding pocket of the receptor [31]. We here focused on the formation of homodimers and heterodimers by Her1, and we found that the numbers of both types of dimer decreased in EGFR mutation-positive NSCLC cell lines treated with EGFR-TKIs, with the
A

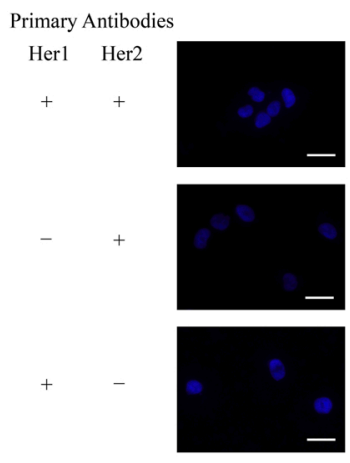

DAPI
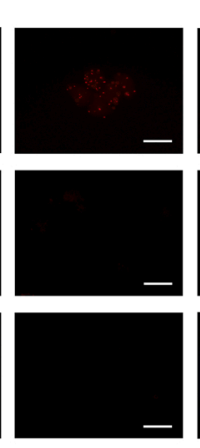

Dimer signal
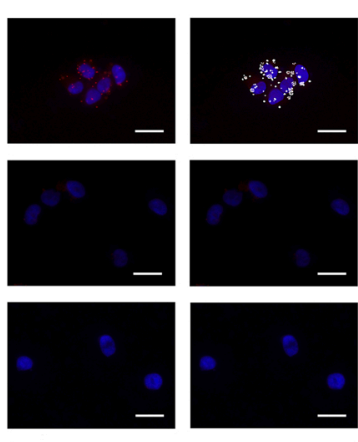

Merged
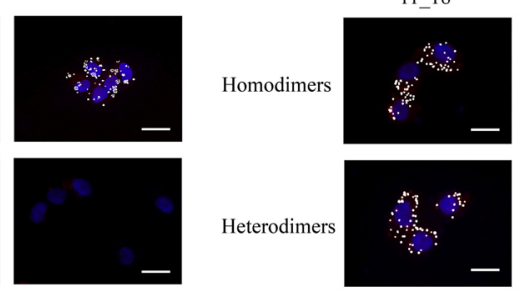

C

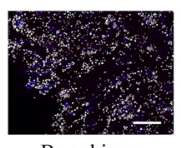

Bone biopsy
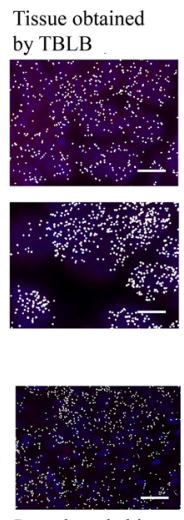

Lymph node biopsy
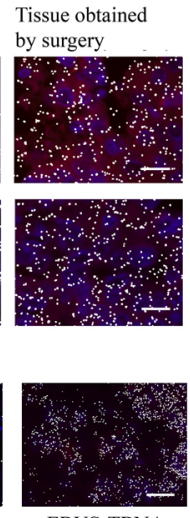

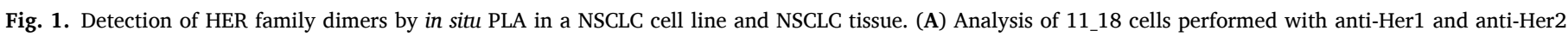

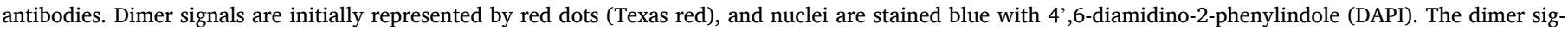

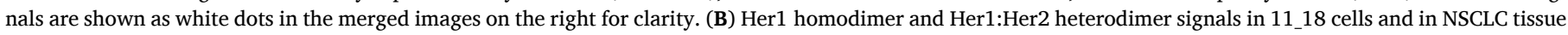

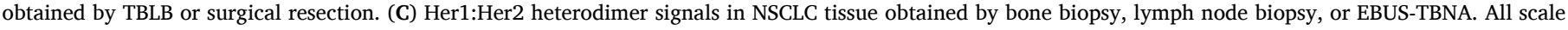
bars, $50 \mu \mathrm{m}$. 
A

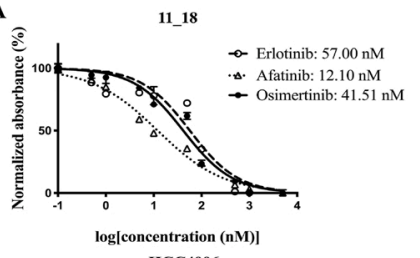

HCC4006

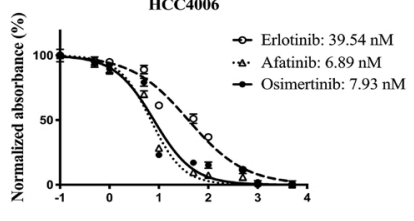

$\log [$ concentration $(\mathrm{nM})]$

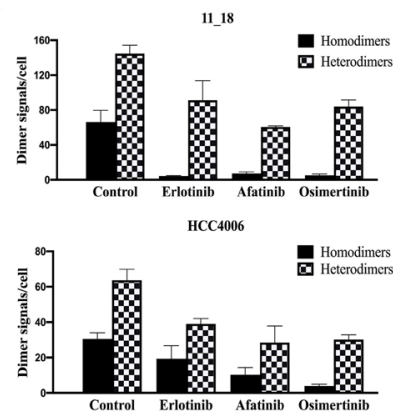

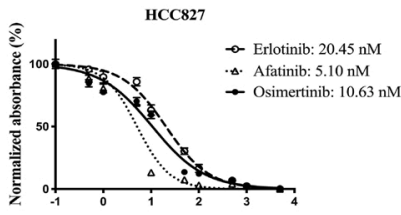

$\log [$ concentration (nM)]

PC9

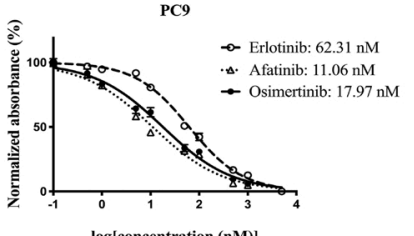

$\log [$ concentration $(\mathrm{nM})]$

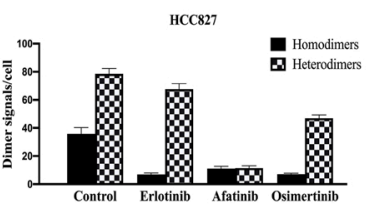

PC9

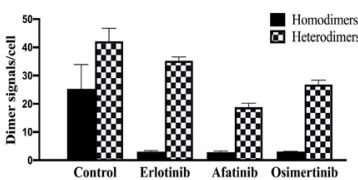

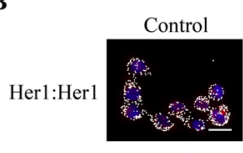

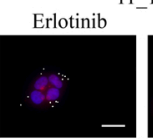

$-18$
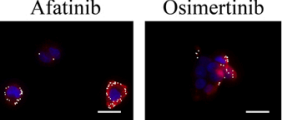

Her1:Her2
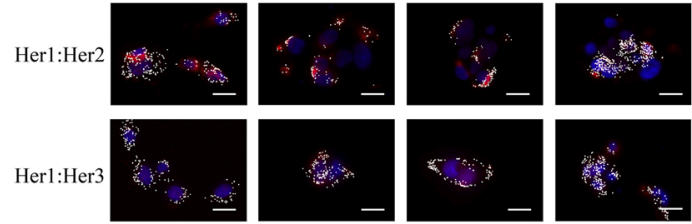

Her1:Her4
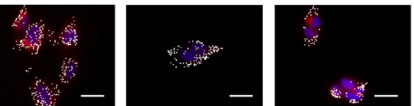

6.

D

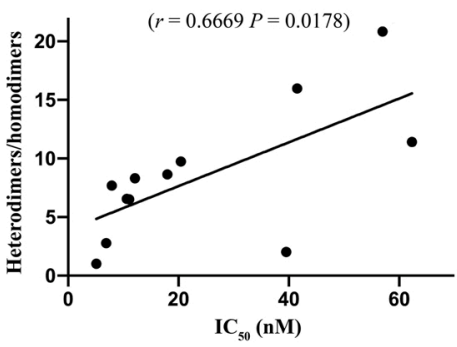

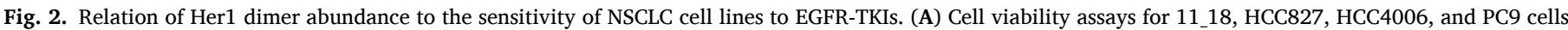

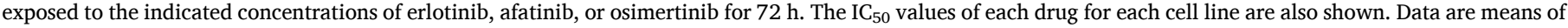

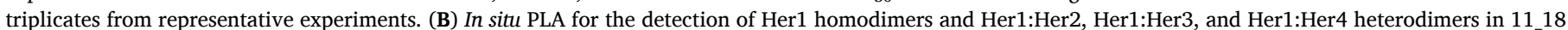

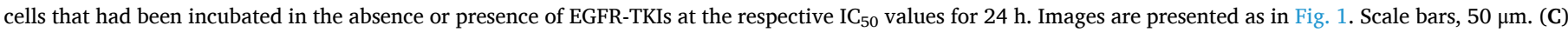

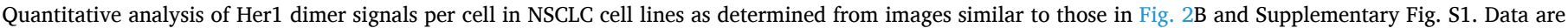

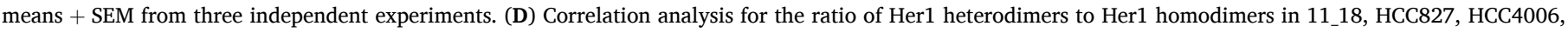
and PC9 cells after EGFR-TKI treatment as in (B) and the corresponding IC $_{50}$ values of erlotinib, afatinib, and osimertinib.

Table 1

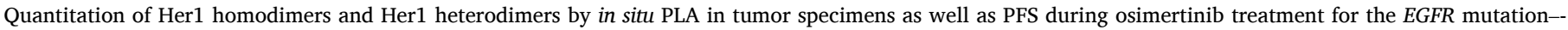
positive NSCLC patients of the study cohort.

\begin{tabular}{|c|c|c|c|c|c|}
\hline Patient & Sample site & Homodimers (/cell) & Heterodimers (/cell) & Heterodimers/homodimers & PFS (days) \\
\hline 1 & Lung lobe & 1.16 & 23.42 & 20.19 & 385 \\
\hline 2 & Bone & 3.35 & 31.95 & 9.54 & 311 \\
\hline 3 & Mediastinum & 2.00 & 18.76 & 9.38 & 389 \\
\hline 4 & Lung lobe & 2.54 & 21.45 & 8.45 & 531 \\
\hline 5 & Lung lobe & 1.55 & 12.41 & 8.00 & 400 \\
\hline 6 & Lung lobe & 2.90 & 22.64 & 7.79 & 256 \\
\hline 7 & Bone & 4.15 & 30.85 & 7.44 & 526 \\
\hline 8 & Lung lobe & 3.62 & 26.33 & 7.27 & 379 \\
\hline 9 & Lung lobe & 4.37 & 23.00 & 5.27 & 591 \\
\hline 10 & Bone & 4.85 & 15.50 & 5.25 & 478 \\
\hline 11 & Lymph node & 2.43 & 12.66 & 5.20 & 1962 \\
\hline 12 & Lung lobe & 5.52 & 27.13 & 4.91 & 979 \\
\hline 13 & Lung lobe & 5.98 & 29.04 & 4.86 & 157 \\
\hline 14 & Lung lobe & 7.81 & 36.76 & 4.71 & 974 \\
\hline 15 & Lung lobe & 5.10 & 22.98 & 4.51 & 591 \\
\hline 16 & Lung lobe & 1.96 & 8.46 & 4.30 & 289 \\
\hline 17 & Pleura & 8.00 & 32.20 & 4.03 & 182 \\
\hline 18 & Lung lobe & 3.22 & 11.43 & 3.55 & 1263 \\
\hline 19 & Lung lobe & 7.81 & 24.96 & 3.20 & 490 \\
\hline 20 & Lung lobe & 12.16 & 38.67 & 3.18 & 1802 \\
\hline 21 & Lung lobe & 3.91 & 11.24 & 2.87 & 672 \\
\hline 22 & Lymph node & 16.00 & 40.48 & 2.53 & 343 \\
\hline 23 & Lung lobe & 13.14 & 29.23 & 2.22 & 1801 \\
\hline 24 & Lymph node & 9.47 & 20.44 & 2.16 & 490 \\
\hline 25 & Lung lobe & 17.19 & 25.40 & 1.48 & 487 \\
\hline 26 & Lung lobe & 13.11 & 17.49 & 1.33 & 203 \\
\hline
\end{tabular}

number of homodimers tending to show a more pronounced response. A recent study found that protein dimerization is related to the antitumor activity of targeted inhibitors [14]. We also found that the ratio of Her1 heterodimers to homodimers in NSCLC cells treated with EGFR-TKIs correlated with the $\mathrm{IC}_{50}$ of these drugs, suggesting that the relative proportions of heterodimers and homodimers of the HER family as 


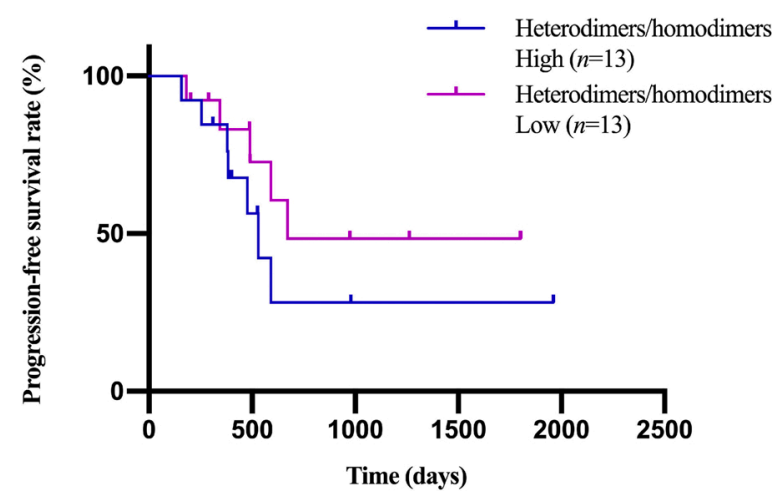

Fig. 3. Kaplan-Meier curves of PFS during osimertinib treatment for EGFRmutated NSCLC patients with a high or low ratio of Her1 heterodimers to Her1 homodimers (according to the median value of 4.79) in tumor specimens collected after they had developed T790M-associated drug resistance during prior treatment with erlotinib or afatinib.

determined by in situ PLA may reflect sensitivity to EGFR-TKIs.

Sensitivity to EGFR-TKIs is strongly associated with the presence of EGFR activating mutations in individuals with NSCLC. Furthermore, NSCLC patients positive for the TKI resistance-conferring T790M mutation of EGFR have been shown to benefit from osimertinib as a secondline treatment $[22,32]$. We examined the relation between the Her1 heterodimer/homodimer ratio in tumor specimens and PFS during osimertinib treatment for NSCLC patients positive for the T790M mutation after first-line treatment with erlotinib or afatinib. A previous study of breast cancer patients revealed that a high level of Her2 homodimers or Her2:Her3 heterodimers was associated with a reduced relapse-free survival and overall survival [9]. We found that NSCLC patients with a high ratio of Her1 heterodimers to Her1 homodimers had a shorter PFS compared with those with a low ratio, suggesting that measurement of HER family dimerization may provide prognostic information for patients with EGFR-mutated NSCLC who receive second-line treatment with osimertinib.

There are several limitations to the present study. Given the small number of patients, the association between the Her1 heterodimer/ homodimer ratio and benefit from EGFR-TKI therapy with regard to second-line treatment with osimertinib will require further confirmation. In addition, given that the T790M mutation accounts for EGFR-TKI resistance in only $\sim 60 \%$ of patients and that osimertinib as well as panHER inhibitors such as afatinib and dacomitinib are now administered as a first-line treatment for NSCLC patients with EGFR mutations, further detailed characterization of the relation between Her1 dimers and EGFR-TKI efficacy is warranted. Moreover, given that heterodimers, such as Her2:Her3 [33], form between members of the HER family other than Her1, further studies are needed to evaluate the relation of such heterodimers to prognosis in NSCLC patients. Finally, we performed only the PLA technique for visualization and quantitative evaluation of homodimers and heterodimers of the HER family. Given that the PLA technique in this setting depends on the affinity between HER family proteins and the corresponding antibodies and that other techniques such as fluorescence resonance energy transfer (FRET) and bioluminescence resonance energy transfer (BRET) for identification of sets of proteins that act in close proximity have emerged [34], comparison of these various techniques for potential clinical application is warranted.

In conclusion, we have shown that the in situ PLA technique allows quantitative assessment of HER family dimers not only in NSCLC cell lines but also in clinical NSCLC specimens obtained from different anatomic sites and by different procedures. Furthermore, NSCLC patients with a high Her1 heterodimer/homodimer ratio had a shorter PFS during second-line treatment with osimertinib than did those with a low ratio. Assessment of HER family dimers may thus provide a predictive marker for the response to EGFR-TKI treatment.
Funding

This work was supported by a Japan Society for the Promotion of Science KAKENHI grant (no. JP 18K 15927).

\section{CRediT authorship contribution statement}

Renpeng Liu: Methodology, Formal analysis, Investigation, Writing - original draft. Keiichi Ota: Conceptualization, Methodology, Validation, Writing - original draft, Writing - review \& editing, Resources, Funding acquisition. Eiji Iwama: Methodology, Validation, Writing review \& editing, Resources. Yasuto Yoneshima: Visualization. Kentaro Tanaka: Visualization. Hiroyuki Inoue: Visualization. Tetsuzo Tagawa: Resources, Visualization. Yoshinao Oda: Resources, Supervision. Masaki Mori: Resources, Supervision. Yoichi Nakanishi: Supervision. Isamu Okamoto: Writing - review \& editing, Visualization, Supervision.

\section{Declaration of Competing Interest}

The authors report no declarations of interest.

\section{Acknowledgments}

We thank the Research Support Center, Research Center for Human Disease Modeling, Graduate School of Medical Sciences, Kyushu University, for technical assistance.

\section{Appendix A. Supplementary data}

Supplementary material related to this article can be found, in the online version, at doi:https://doi.org/10.1016/j.lungcan.2021.05.023.

\section{References}

[1] J. Mendelsohn, J. Baselga, Status of epidermal growth factor receptor antagonists in the biology and treatment of cancer, J. Clin. Oncol. 21 (14) (2003) 2787-2799.

[2] E. Kovacs, J.A. Zorn, Y. Huang, T. Barros, J. Kuriyan, A structural perspective on the regulation of the epidermal growth factor receptor, Annu. Rev. Biochem. 84 (2015) 739-764.

[3] N.V. Sergina, M.M. Moasser, The HER family and cancer: emerging molecular mechanisms and therapeutic targets, Trends Mol. Med. 13 (12) (2007) 527-534.

[4] Y. Yarden, M.X. Sliwkowski, Untangling the ErbB signalling network, Nat. Rev. Mol. Cell Biol. 2 (2) (2001) 127-137.

[5] S. Lamouille, J. Xu, R. Derynck, Molecular mechanisms of epithelial-mesenchymal transition, Nat. Rev. Mol. Cell Biol. 15 (3) (2014) 178-196.

[6] F. Janku, D.J. Stewart, R. Kurzrock, Targeted therapy in non-small-cell lung cancer-is it becoming a reality? Nat. Rev. Clin. Oncol. 7 (7) (2010) 401-414.

[7] Y. Ling, X. Yang, W. Li, Z. Li, L. Yang, T. Qiu, L. Guo, L. Dong, L. Li, J. Ying, D. Lin, Overexpression of mutant EGFR protein indicates a better survival benefit from EGFR-TKI therapy in non-small cell lung cancer, Oncotarget 7 (33) (2016) $52862-52869$.

[8] S.L. Wang, G.X. Zhong, X.W. Wang, F.Q. Yu, D.F. Weng, X.X. Wang, J.H. Lin, Prognostic significance of the expression of HER family members in primary osteosarcoma, Oncol. Lett. 16 (2) (2018) 2185-2194.

[9] M. Spears, K.J. Taylor, A.F. Munro, C.A. Cunningham, E.A. Mallon, C.J. Twelves, D. A. Cameron, J. Thomas, J.M. Bartlett, In situ detection of HER2:HER2 and HER2: HER3 protein-protein interactions demonstrates prognostic significance in early breast cancer, Breast Cancer Res. Treat. 132 (2) (2012) 463-470.

[10] H. Yasuda, S. Kobayashi, D.B. Costa, EGFR exon 20 insertion mutations in nonsmall-cell lung cancer: preclinical data and clinical implications, Lancet Oncol. 13 (1) (2012) e23-e31.

[11] Y. Kobayashi, T. Mitsudomi, Not all epidermal growth factor receptor mutations in lung cancer are created equal: perspectives for individualized treatment strategy, Cancer Sci. 107 (9) (2016) 1179-1186.

[12] C.K. Lee, C. Brown, R.J. Gralla, V. Hirsh, S. Thongprasert, C.M. Tsai, E.H. Tan, J. C. Ho, T. Chu da, A. Zaatar, J.A. Osorio Sanchez, V.V. Vu, J.S. Au, A. Inoue, S. M. Lee, V. Gebski, J.C. Yang, Impact of EGFR inhibitor in non-small cell lung cancer on progression-free and overall survival: a meta-analysis, J. Natl. Cancer Inst. 105 (9) (2013) 595-605.

[13] J. Zhao, Y. Xia, Targeting HER2 alterations in non-small-cell lung cancer: a comprehensive review, JCO Precis. Oncol. 4 (2020) 411-425.

[14] S. Oasa, V. Vukojevic, R. Rigler, I.F. Tsigelny, J.P. Changeux, L. Terenius, A strategy for designing allosteric modulators of transcription factor dimerization, Proc. Natl. Acad. Sci. U. S. A. 117 (5) (2020) 2683-2686. 
[15] T. Koga, Y. Kobayashi, K. Tomizawa, K. Suda, T. Kosaka, Y. Sesumi, T. Fujino, M. Nishino, S. Ohara, M. Chiba, M. Shimoji, T. Takemoto, M. Suzuki, P.A. Janne, T. Mitsudomi, Activity of a novel HER2 inhibitor, poziotinib, for HER2 exon 20 mutations in lung cancer and mechanism of acquired resistance: an in vitro study, Lung Cancer 126 (2018) 72-79.

[16] D. Westover, J. Zugazagoitia, B.C. Cho, C.M. Lovly, L. Paz-Ares, Mechanisms of acquired resistance to first- and second-generation EGFR tyrosine kinase inhibitors, Ann. Oncol. 29 (suppl_1) (2018) i10-i19.

[17] S. Kobayashi, T.J. Boggon, T. Dayaram, P.A. Janne, O. Kocher, M. Meyerson, B. E. Johnson, M.J. Eck, D.G. Tenen, B. Halmos, EGFR mutation and resistance of nonsmall-cell lung cancer to gefitinib, N. Engl. J. Med. 352 (8) (2005) 786-792.

[18] R. Rosell, E. Carcereny, R. Gervais, A. Vergnenegre, B. Massuti, E. Felip, R. Palmero, R. Garcia-Gomez, C. Pallares, J.M. Sanchez, R. Porta, M. Cobo, P. Garrido, F. Longo, T. Moran, A. Insa, F. De Marinis, R. Corre, I. Bover, A. Illiano, E. Dansin, J. de Castro, M. Milella, N. Reguart, G. Altavilla, U. Jimenez, M. Provencio, M.A. Moreno, J. Terrasa, J. Muñoz-Langa, J. Valdivia, D. Isla, M. Domine, O. Molinier, J. Mazieres, N. Baize, R. Garcia-Campelo, G. Robinet, D. Rodriguez-Abreu, G. Lopez-Vivanco, V. Gebbia, L. Ferrera-Delgado, P. Bombaron, R. Bernabe, A. Bearz, A. Artal, E. Cortesi, C. Rolfo, M. SanchezRonco, A. Drozdowskyj, C. Queralt, I. de Aguirre, J.L. Ramirez, J.J. Sanchez, M. A. Molina, M. Taron, L. Paz-Ares, Erlotinib versus standard chemotherapy as firstline treatment for European patients with advanced EGFR mutation-positive nonsmall-cell lung cancer (EURTAC): a multicentre, open-label, randomised phase 3 trial, Lancet Oncol. 13 (3) (2012) 239-246.

[19] W. Pao, V.A. Miller, K.A. Politi, G.J. Riely, R. Somwar, M.F. Zakowski, M.G. Kris, H. Varmus, Acquired resistance of lung adenocarcinomas to gefitinib or erlotinib is associated with a second mutation in the EGFR kinase domain, PLoS Med. 2 (3) (2005) e73.

[20] Z. Piotrowska, L.V. Sequist, Treatment of EGFR-mutant lung cancers after progression in patients receiving first-line EGFR tyrosine kinase inhibitors: a review, JAMA Oncol. 2 (7) (2016) 948-954.

[21] C.-S. Tan, D. Gilligan, S. Pacey, Treatment approaches for EGFR-inhibitor-resistant patients with non-small-cell lung cancer, Lancet Oncol. 16 (9) (2015) e447-e459.

[22] T.S. Mok, Y.L. Wu, M.J. Ahn, M.C. Garassino, H.R. Kim, S.S. Ramalingam, F. A. Shepherd, Y. He, H. Akamatsu, W.S. Theelen, C.K. Lee, M. Sebastian, A. Templeton, H. Mann, M. Marotti, S. Ghiorghiu, V.A. Papadimitrakopoulou, A. Investigators, Osimertinib or platinum-pemetrexed in EGFR T790M-positive lung cancer, N. Engl. J. Med. 376 (7) (2017) 629-640.

[23] A. Klaesson, K. Grannas, T. Ebai, J. Heldin, B. Koos, M. Leino, D. Raykova, J. Oelrich, L. Arngarden, O. Soderberg, U. Landegren, Improved efficiency of in situ protein analysis by proximity ligation using UnFold probes, Sci. Rep. 8 (1) (2018), 5400.

[24] G. Gremel, K. Grannas, L.A. Sutton, F. Ponten, A. Zieba, In situ protein detection for companion diagnostics, Front. Oncol. 3 (2013) 271.

[25] K. Ota, T. Harada, K. Otsubo, A. Fujii, Y. Tsuchiya, K. Tanaka, I. Okamoto, Y. Nakanishi, Visualization and quantitation of epidermal growth factor receptor homodimerization and activation with a proximity ligation assay, Oncotarget 8 (42) (2017) 72127-72132.

[26] K. Ota, K. Azuma, A. Kawahara, S. Hattori, E. Iwama, J. Tanizaki, T. Harada, K. Matsumoto, K. Takayama, S. Takamori, M. Kage, T. Hoshino, Y. Nakanishi, I. Okamoto, Induction of PD-L1 expression by the EML4-ALK oncoprotein and downstream signaling pathways in non-small cell lung cancer, Clin. Cancer Res. 21 (17) (2015) 4014-4021.

[27] A.S. Gajadhar, E. Bogdanovic, D.M. Munoz, A. Guha, In situ analysis of mutant EGFRs prevalent in glioblastoma multiforme reveals aberrant dimerization, activation, and differential response to anti-EGFR targeted therapy, Mol. Cancer Res. 10 (3) (2012) 428-440.

[28] C.D. Fichter, V. Gudernatsch, C.M. Przypadlo, M. Follo, G. Schmidt, M. Werner, S. Lassmann, ErbB targeting inhibitors repress cell migration of esophageal squamous cell carcinoma and adenocarcinoma cells by distinct signaling pathways, J. Mol. Med. (Berl.) 92 (11) (2014) 1209-1223.

[29] S.S. Sridhar, L. Seymour, F.A. Shepherd, Inhibitors of epidermal-growth-factor receptors: a review of clinical research with a focus on non-small-cell lung cancer, Lancet Oncol. 4 (7) (2003) 397-406.

[30] M.A. Lemmon, J. Schlessinger, Cell signaling by receptor tyrosine kinases, Cell 141 (7) (2010) 1117-1134.

[31] J. Baselga, C.L. Arteaga, Critical update and emerging trends in epidermal growth factor receptor targeting in cancer, J. Clin. Oncol. 23 (11) (2005) 2445-2459.

[32] P.A. Janne, J.C. Yang, D.W. Kim, D. Planchard, Y. Ohe, S.S. Ramalingam, M.J. Ahn, S.W. Kim, W.C. Su, L. Horn, D. Haggstrom, E. Felip, J.H. Kim, P. Frewer, M. Cantarini, K.H. Brown, P.A. Dickinson, S. Ghiorghiu, M. Ranson, AZD9291 in EGFR inhibitor-resistant non-small-cell lung cancer, N. Engl. J. Med. 372 (18) (2015) 1689-1699.

[33] A. Hirata, F. Hosoi, M. Miyagawa, S. Ueda, S. Naito, T. Fujii, M. Kuwano, M. Ono, HER2 overexpression increases sensitivity to gefitinib, an epidermal growth factor receptor tyrosine kinase inhibitor, through inhibition of HER2/HER3 heterodimer formation in lung cancer cells, Cancer Res. 65 (10) (2005) 4253-4260.

[34] P. Lonn, U. Landegren, Close encounters - probing proximal proteins in live or fixed cells, Trends Biochem. Sci. 42 (7) (2017) 504-515. 